\title{
Rheumatoid arthritis in workers exposed to silica in the pottery industry
}

\author{
Susan Turner, Nicola Cherry
}

\begin{abstract}
Objective-To investigate the relation between rheumatoid arthritis and occupational exposure to silica in pottery and related industries.

Methods-Medical records of 8325 men and women born 1916-45 and employed in pottery, refractory material (aluminosilicate or silica), and sandstone industries were examined to identify cases of rheumatoid arthritis. Medical and employment histories were extracted for cases and matched referents. Indices of duration, cumulative exposure, and mean silica concentration were compiled. Conditional logistic regression was used to investigate the relation between rheumatoid arthritis and indices of exposure, having allowed for potential confounders of smoking, employment in the coal mining industry, and number of pregnancies.

Results-58 Cases of rheumatoid arthritis (43 men, 15 women) were identified. Cases had significantly shorter duration of exposure than referents. There was no significant difference between cases and referents in mean silica concentration. Men who had worked in the coal mining industry were particularly at risk (odds ratio 5.36, 95\% confidence interval 1.92 to 15.03 ).

Conclusion-There was no evidence of increased risk of developing rheumatoid arthritis after occupational exposure to silica at mean exposures within the current United Kingdom exposure limits. (Occup Environ Med 2000;57:443-447)
\end{abstract}

Keywords: rheumatoid arthritis; silica; occupation

In the early part of the 20th century the lung disease found in many dusty occupations was shown to be caused by inhalation of silica dust. ${ }^{1}$ More recent reports suggest that either occupational exposure to silica itself, or the resulting lung fibrosis (silicosis), may be associated with conditions extending beyond the respiratory system, including autoimmune disorders. ${ }^{2}$

Interest in the relation between rheumatoid arthritis and silica arose initially from the finding of distinctive opacities on chest radiographs of coal miners with rheumatoid arthritis. ${ }^{3}$ Subsequent epidemiological studies confirmed that workers exposed to silica who had rheumatoid arthritis were more likely than others with similar exposure to develop lung fibrosis. ${ }^{45}$ Although information from these studies of Welsh coal miners ${ }^{4}$ and South African gold miners ${ }^{5}$ did not suggest that exposure to silica increased the risk of rheumatoid arthritis, other evidence gave some support to this idea. In Finland ${ }^{6}$ granite workers received more disability pensions than expected for rheumatoid arthritis. Investigators in the United States showed ${ }^{7}$ that among 991 granite workers, death certificates mentioned arthritis more often than expected; only five of the 17 certificates mentioning arthritis specified that it was rheumatoid. Further evidence came from studies of silicotic workers. Workers with abnormal chest radiographs but without rheumatoid arthritis had high rates of positive serological findings, of rheumatoid factor in coal miners ${ }^{8}$ and of antinuclear antibodies in sandblasters. ${ }^{9}$ Medical records of silicotic workers in Michigan, USA ${ }^{10}$ suggested more cases of rheumatoid arthritis than in the general population but the criteria for diagnosis differed in the case and comparison series. None of these findings is, of itself, conclusive but together they raise sufficient questions to warrant further study of the role of silica in the onset of rheumatoid arthritis.

In the United Kingdom, manufacture of pottery is largely concentrated in north Staffordshire and is a major contributor to the industry of the district. Reports of effects on health within pottery and related industries resulted in the requirement for statutory medical examination of workers, ${ }^{11}$ and these were undertaken for more than 60 years, until 1984 when the specific provision was revoked. Although the legislation was initially focused on men in certain trades, medical surveillance was gradually extended to cover more trades, and from 1950, women workers. Records for workers within the pottery and related industries are held by the Medical Boarding Centre at Stoke-on-Trent (now the Benefits Agency of the Department of Social Security (DSS)) and contain a standardised occupational and medical history, physical examination, and chest radiographs. These records provided the opportunity to investigate whether rheumatoid arthritis was diagnosed more often in those workers with higher exposure to silica. Contemporary records were used of both disease and potential confounders (smoking, ${ }^{12}$ exposure to coal dust, ${ }^{34}$ and parity ${ }^{13}$ ) thought to be related to rheumatoid arthritis.

\section{Methods}

A case-referent study was carried out, nested within a cohort of 8325 (6353 men and 1972 women) pottery, sandstone, and refractory material workers born between 1916 and 1945 who underwent medical surveillance under the Pottery Regulations at the DSS Medical Boarding Centre in Stoke-on-Trent. 
DEFINITION OF CASE AND REFERENT

Under the legislation, medical examinations were performed by a physician from the Boarding Centre at appointments (initial examination) and then at 2 yearly intervals (periodic examinations). For many workers, employed before the legislation applied to their trade or sex, the first examination took place long after their initial recruitment as part of a "catch up" programme. At each examination a form was used which required the physician to record, among other medical data, whether or not the employee had been diagnosed as having rheumatoid arthritis.

For the present study, cases of rheumatoid arthritis were defined as those subjects for whom the examining physician had responded yes to the question on rheumatoid arthritis on the last available medical examination form. The criteria used by a physician in reaching this diagnosis were not recorded: in all but two cases the physician added clinical comments rather than simply selecting the yes response, suggesting consideration had been given to the question. No clinical validation was attempted. The date of diagnosis was taken as that of the first examination at which rheumatoid arthritis was recorded. Referents were selected from all subjects who had had a medical examination after the date of the diagnostic medical examination of the case. Before a referent was accepted every medical form was scrutinised to ensure that rheumatoid arthritis had not been recorded before that date.

Four referents were matched to each case on sex, and as closely as possible, on date of birth and date of first exposure to pottery. Matching of referents for date of birth was attained within 4 years for $98.8 \%$ men and $93.3 \%$ women. The remaining two male referents had differences of 4.4 and 5.6 years, and four female referents had differences between 4.3 and 5.5 years. For date of starting work in the pottery or related industries, matching of referents was attained within 4 years for $99.4 \%$ men and $98.3 \%$ women. The remaining male referent had a difference of 4.2 years, and one female referent had a difference of 5.7 years.

\section{MEASUREMENT OF EXPOSURE}

The exposure estimates were made from occupational histories extracted from detailed records kept at the medical examinations; all estimation was done without knowledge of diagnosis of the subject. The methods and validation against radiographic change have been described elsewhere. ${ }^{14} 15$

At the first medical, whenever this was held, a complete occupational history was taken, with particular emphasis on dusty jobs. This record was brought up to date at each subsequent medical examination. Three measures of exposure to respirable silica were used; duration, cumulative exposure, and mean silica concentration.

Cumulative duration of exposure

Cumulative duration of exposure was calculated from date of first employment. The periods in each job held were summed, with the final date as the date of diagnosis of rheumatoid arthritis or, for referents, the date of diagnosis of the corresponding case.

\section{Cumulative exposure}

Cumulative exposure, expressed as $\mu \mathrm{g} / \mathrm{m}^{3} \times \mathrm{y}$ of respirable silica was calculated with the exposure matrix developed by Burgess ${ }^{15}$ for work in the pottery industry, summing time weighted exposures for each job held. A few subjects had been exposed to silica in the sandstone or refractory material industries and for these the occupational hygienist estimated exposure from records of environmental sampling within these industries.

\section{Mean silica concentration}

Mean silica concentration was calculated by dividing the cumulative exposure for each person by the cumulative duration of exposure and was expressed as $\mu \mathrm{g} / \mathrm{m}^{3}$.

MEASUREMENT OF POTENTIAL CONFOUNDERS

Past and present smoking habits were extracted from records of first and last medical examinations to ascertain smoking status (ever or never smoked). Any work within "dusty trades" other than pottery was established from detailed job histories recorded at initial and periodic medical reviews and a total duration in each industry - for example, coal—was calculated by summing separate periods. For women, information on the number of children or information on pregnancies was extracted from all available medical records and parity status (parous or nulliparous) established as accurately as possible.

Chest radiograph readings were performed routinely in the month after the initial or periodic medical examinations. A reading of $1 / 0$ (International Labour Organisation (ILO) classification) ${ }^{16}$ or more for small parenchymal opacities was considered to indicate pneumoconiosis in this study.

STATISTICAL METHODS

Conditional logistic regression was used to examine the relation between exposure and presence or absence of rheumatoid arthritis. Each exposure measurement was examined independently and odds ratios (ORs) with 95\% confidence intervals (95\% CIs) were calculated. Odds ratios and 95\% CIs were also calculated after adjusting for smoking and history of working in coal mining (men) or number of children (women). To assist in presentation of results, duration/10 (years), cumulative exposure $/ 1000\left(\mu \mathrm{g} / \mathrm{m}^{3} \times \mathrm{y}\right)$ and mean silica concentration $/ 100\left(\mu \mathrm{g} / \mathrm{m}^{3}\right)$ were used in conditional logistic regression analyses.

\section{Results}

Within the cohort 58 people were found to have rheumatoid arthritis, 43 men and 15 women. Matching of cases and referents on age and date of starting work was close, with a mean (SD) age of workers at the start of employment in pottery and related industries of 23.7 (10.0) years for cases and $23.4(10.1)$ years for referents. The mean year of first 


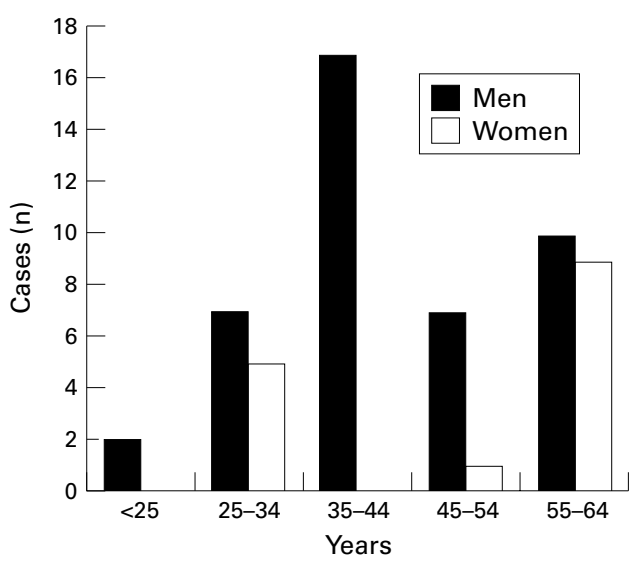

Figure 1 Age at diagnosis of rheumatoid arthritis.

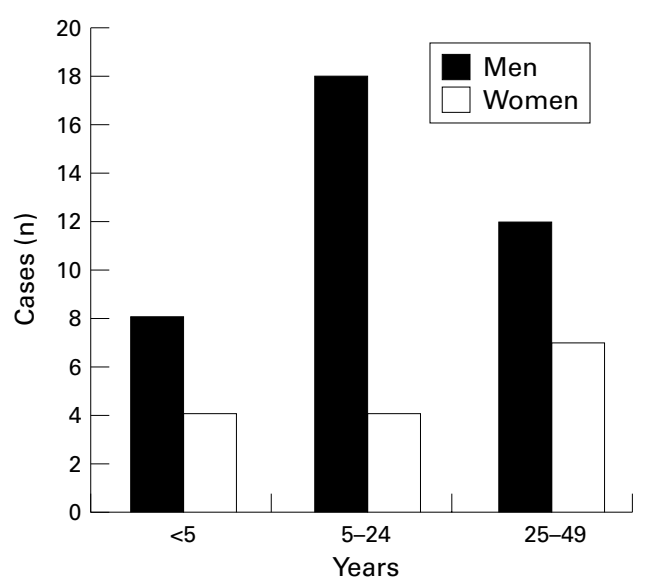

Figure 2 Time from start of employment to diagnosis of rheumatoid arthritis.

employment in the pottery industry was 1956 for both cases and referents. Women were slightly older (mean age 24.5 years) than men (mean age 23.1 years) when starting work in the industry. Women also started slightly later (mean year 1958) than men (mean year 1956).

Figure 1 shows the age at diagnosis of rheumatoid arthritis in this study. Women were older than men at the time of diagnosis, half being diagnosed between ages 57 and 61 .

For 25 of the 58 cases the diagnosis of rheumatoid arthritis was made at the first medical examination, on average 15.8 years after start-

Table 1 Mean exposure concentration $\left(\mu \mathrm{g} / \mathrm{m}^{3}\right)$ by time between first employment in the potteries and diagnosis of rheumatoid arthritis

\begin{tabular}{|c|c|c|c|c|c|c|}
\hline \multirow[b]{2}{*}{ Time to diagnosis } & \multicolumn{2}{|l|}{ Men } & \multicolumn{2}{|l|}{ Women } & \multicolumn{2}{|l|}{ All } \\
\hline & Cases & Referents & Cases & Referents & Cases & Referents \\
\hline \multicolumn{7}{|l|}{ <5 y: } \\
\hline Mean & 109.8 & 97.2 & 100.3 & 96.7 & 106.6 & 97.0 \\
\hline $\mathrm{SD}$ & 51.1 & 59.7 & 54.4 & 62.5 & 49.9 & 60.0 \\
\hline $\mathrm{n}$ & 8 & 32 & 4 & 16 & 12 & 48 \\
\hline \multicolumn{7}{|l|}{$5<25 \mathrm{y}:$} \\
\hline Mean & 133.4 & 148.5 & 88.0 & 95.2 & 124.2 & 138.8 \\
\hline SD & 55.0 & 75.6 & 91.7 & 106.8 & 63.6 & 84.0 \\
\hline $\mathrm{n}$ & 18 & 72 & 4 & 16 & 22 & 88 \\
\hline \multicolumn{7}{|l|}{$25<50 \mathrm{y}:$} \\
\hline Mean & 153.5 & 152.0 & 155.2 & 129.8 & 154.0 & 145.5 \\
\hline SD & 91.4 & 67.7 & 108.6 & 56.9 & 94.3 & 65.2 \\
\hline $\mathrm{n}$ & 17 & 68 & 7 & 28 & 24 & 96 \\
\hline \multicolumn{7}{|l|}{ Overall: } \\
\hline Mean & 137.0 & 140.3 & 121.3 & 111.7 & 132.9 & 132.9 \\
\hline SD & 71.4 & 72.4 & 92.8 & 75.2 & 76.9 & 74.1 \\
\hline $\mathrm{n}$ & 43 & 172 & 15 & 60 & 58 & 232 \\
\hline
\end{tabular}

ing work in the pottery industry. These prevalent cases contained a disproportionately high number of women, who had been included under the legislation much later than men. The distribution of cases by time from first pottery employment to diagnosis is shown in figure 2 . Initially it seemed likely that cases attributed to pottery exposure would be less in evidence in those with a diagnosis within 5 years of first exposure.

Data on smoking, a potential confounder, were available for all cases and for all but one of the referents. Just under a quarter $(22.8 \%)$ of the cases and referents had never smoked at the time of diagnosis of the case, roughly the same number $(21.7 \%)$ were ex-smokers, and just over half $(55.2 \%)$ were current smokers. The proportion who had never smoked was similar in cases $(20.7 \%)$ and referents $(23.3 \%)$.

Information was extracted on time spent in dusty jobs outside the pottery, refractory materials, and sandstone industries. Twenty men had worked in the coal mining industry; 10/43 cases and 10/172 referents. Most were employed in coal mining before work in the pottery industry, but two cases and one referent had breaks from employment within pottery work to enter coal mining. Further examination of job details showed that nine cases had worked underground in coal mining, although only five referents had done so; the remaining six men were employed as hauliers, drivers, or surface maintenance workers. Few women had been exposed to dust hazards apart from silica within pottery work, but one case and one referent had worked in the rubber industry and had potential exposure to talc in this environment.

For the 75 women in the study, information on number of children was available for $13 / 15$ cases and 48/60 referents. The mean (SD) number of children was slightly higher for cases $(2.5(1.7))$ than referents $(1.9(1.2))$, but cases and referents both had a median value of 2 . Nearly a quarter $(3 / 13)$ of cases but only $6.3 \%$ (3/48) referents had four or more children. Parity was slightly higher $(92.3 \%)$ in cases than referents $(87.5 \%)$.

At least one chest radiograph was available for $56 / 58$ cases and $227 / 232$ referents. The last available radiograph at the point of diagnosis of the case was used. Only one person (a female referent) was found to have a reading of small parenchymal opacities equal to or greater than $1 / 0$.

Of the three measures of exposure considered, it was thought that concentration would be of the greatest interest. The design was such that, in matching on date of starting and accumulating only to the date of diagnosis of the case, little variation in the time of the exposure between cases and referent was expected, unless cases took more time away from the industry, for other employment, illness, or domestic responsibilities. Mean concentration of exposure is shown by time to diagnosis in table 1 . Overall, the mean concentration did not differ between cases and referents. Female cases diagnosed at least 25 years after first exposure seemed to have somewhat higher concentrations than the 
Table 2 Mean duration (y) in pottery work by time between first employment in potteries and diagnosis of rheumatoid arthritis

\begin{tabular}{|c|c|c|c|c|c|c|}
\hline \multirow[b]{2}{*}{ Time to diagnosis } & \multicolumn{2}{|l|}{ Men } & \multicolumn{2}{|c|}{ Women } & \multicolumn{2}{|l|}{ All } \\
\hline & Cases & Referents & Cases & Referents & Cases & Referents \\
\hline \multicolumn{7}{|l|}{$<5 \mathrm{y}:$} \\
\hline Mean & 3.4 & 3.5 & 1.9 & 2.4 & 2.9 & 3.1 \\
\hline SD & 1.4 & 2.3 & 1.3 & 1.5 & 1.5 & 2.1 \\
\hline $\mathrm{n}$ & 8 & 32 & 4 & 16 & 12 & 48 \\
\hline \multicolumn{7}{|l|}{$5<25 \mathrm{y}:$} \\
\hline Mean & 14.0 & 15.2 & 12.5 & 14.1 & 13.7 & 15.0 \\
\hline SD & 5.1 & 6.1 & 2.6 & 4.4 & 4.7 & 5.8 \\
\hline $\mathrm{n}$ & 18 & 72 & 4 & 16 & 22 & 88 \\
\hline \multicolumn{7}{|l|}{$25<50 \mathrm{y}:$} \\
\hline Mean & 27.1 & 31.2 & 29.8 & 36.5 & 27.9 & 32.7 \\
\hline SD & 6.9 & 6.7 & 9.2 & 7.3 & 7.5 & 7.2 \\
\hline $\mathrm{n}$ & 17 & 68 & 7 & 28 & 24 & 96 \\
\hline \multicolumn{7}{|l|}{ Overall: } \\
\hline Mean & 17.2 & 19.4 & 17.8 & 21.4 & 17.4 & 19.9 \\
\hline $\mathrm{SD}$ & 10.5 & 12.0 & 13.8 & 15.8 & 11.3 & 13.1 \\
\hline $\mathrm{n}$ & 43 & 172 & 15 & 60 & 58 & 232 \\
\hline
\end{tabular}

referents but with few cases this difference did not reach significance $(\mathrm{p}=0.4)$.

Gaps in service were more common in cases than referents, and despite the restrictions imposed by matching on time of entry and exit, cases spent less time in pottery work than the referents (table 2). This was found for both men and women, and was present regardless of the duration of time between starting work and diagnosis.

Because little difference was apparent in mean concentration, and cumulative duration was shorter in cases, the index reflecting cumulative exposure (duration $\times$ mean intensity) was also somewhat lower in cases (2515 $\left.\mu \mathrm{g} / \mathrm{m}^{3} \times \mathrm{y}\right)$ than referents $\left(2872 \mu \mathrm{g} / \mathrm{m}^{3} \times \mathrm{y}\right)$. The only groups with slightly greater cumulative exposure in cases were men diagnosed within 5 years of starting (cases $383 \mu \mathrm{g} / \mathrm{m}^{3} \times \mathrm{y}$, referents $359 \mu \mathrm{g} / \mathrm{m}^{3} \times \mathrm{y}$ ) and women diagnosed after more than 25 years (cases $4912 \mu \mathrm{g} / \mathrm{m}^{3} \times \mathrm{y}$, referents $\left.4746 \mu \mathrm{g} / \mathrm{m}^{3} \times \mathrm{y}\right)$.

Odds ratios for the whole sample were calculated separately for duration, cumulative exposure, and mean silica concentration, each entered as a continuous variable (table 3 ). The unadjusted OR for duration was significantly less than $1.0(\mathrm{p}<0.001)$ and that for cumulative exposure was also reduced for men $(p<0.05)$. The OR for mean silica concentration was close to 1.0 for the population as a whole.

The OR for smoking (ever or never) and rheumatoid arthritis was not significantly raised (OR 1.20, 95\% CI 0.57 to 2.49 ), but was

Table 3 Odds ratios for rheumatoid arthritis by each exposure variable (conditional logistic regression analysis)

\begin{tabular}{|c|c|c|c|c|c|c|}
\hline \multirow{2}{*}{$\begin{array}{l}\text { Exposure } \\
\text { index }\end{array}$} & \multicolumn{2}{|l|}{ All } & \multicolumn{2}{|l|}{ Men } & \multicolumn{2}{|l|}{ Women } \\
\hline & Unadjusted & Adjusted $^{\star}$ & Unadjusted & Adjustedt & Unadjusted & Adjusted $\ddagger$ \\
\hline \multicolumn{7}{|c|}{ Duration/10 (y): } \\
\hline OR & 0.31 & 0.31 & 0.27 & 0.29 & 0.36 & 0.61 \\
\hline $95 \% \mathrm{CI}$ & 0.16 to 0.60 & 0.16 to 0.61 & 0.11 to 0.68 & 0.11 to 0.76 & 0.13 to 0.98 & 0.18 to 2.02 \\
\hline \multicolumn{7}{|c|}{ Cumulative exposure $/ 1000\left(\mu \mathrm{g} / \mathrm{m}^{3} \times \mathrm{y}\right)$ : } \\
\hline OR & 0.81 & 0.80 & 0.73 & 0.71 & 0.96 & 1.13 \\
\hline $95 \% \mathrm{CI}$ & 0.64 to 1.02 & 0.64 to 1.02 & 0.54 to 0.99 & 0.52 to 0.97 & 0.66 to 1.38 & 0.73 to 1.73 \\
\hline \multicolumn{7}{|c|}{ Mean silica concentration $/ 100\left(\mu \mathrm{g} / \mathrm{m}^{3}\right)$ : } \\
\hline OR & 0.99 & 0.97 & 0.89 & 0.79 & 1.49 & 1.56 \\
\hline $95 \% \mathrm{CI}$ & 0.58 to 1.73 & 0.56 to 1.70 & 0.47 to 1.68 & 0.40 to 1.57 & 0.47 to 4.68 & 0.36 to 6.75 \\
\hline Cases (n) & 58 & 58 & 43 & 43 & 15 & 13 \\
\hline
\end{tabular}

*Adjusted for ever or never smoking.

†Adjusted for ever or never smoking + history of working in the coal mining industry.

‡Adjusted for ever or never smoking + number of children. higher for men (OR $1.89,95 \%$ CI 0.67 to 5.32 ) than women (OR 0.64, $95 \%$ CI 0.20 to 2.02 ). Adjustment for smoking had no important effect on the ORs for duration, cumulative exposure, or mean silica concentration in the study group as a whole.

Other potential confounders were exposure to coal dust for men and parity for women. Male cases were significantly more likely to have worked in the coal mining industry than referents (OR 5.36, 95\% CI 1.92 to 15.03) and, if they had, to have worked there slightly longer (cases: mean 3.6 years, referents: mean 3.3 years). The OR increased to 8.47 (95\% CI 2.59 to 27.66) when underground mining work was considered. In women, the relation between number of children and rheumatoid arthritis was not significant either when number of children was entered as a continuous variable (OR $1.45,95 \%$ CI 0.88 to 2.38 ) or when women were categorised as either parous or nulliparous (OR $1.51,95 \%$ CI 0.17 to 13.05 ).

In men, adjustment for smoking and history of work in the coal mining industry did not alter notably the estimated OR for rheumatoid arthritis for any of the measures of exposure; the upper band of the $95 \%$ CI remained below 1.0 for both duration and cumulative exposure in men. In women, however, allowance for smoking and number of children removed any relation to duration of exposure.

\section{Discussion}

Records from this large cohort of pottery and related workers were used to examine whether those with rheumatoid arthritis had greater exposure to respirable silica than matched referents without the disease. No relation was found between mean concentration of exposure to silica and rheumatoid arthritis in men; in women the OR was raised but with a very wide $95 \%$ CI. Cases with arthritis were found to have significantly shorter durations of exposure than their matched referents; in men, but not women, this was still apparent after allowance for confounding. Within the constraints of the study, there seemed to be no clear evidence of increased risk attributable to exposure to silica; this is consistent with the results of earlier studies of mining cohorts. ${ }^{45}$

The limitations of the study are those of power, uncertainty of diagnosis, dependence of diagnosis on continuity of employment, and lack of a clear date of onset in prevalent cases. Potential strengths are the size of the cohort, the contemporary data on rheumatoid arthritis and confounders, and the separation of exposure assessment and diagnosis.

The power of the study was reasonable overall (an $80 \%$ power assuming $\alpha=0.05$ (two sided) to detect an OR of 2.5) but for women the numbers were too small to allow secure conclusions either about the effects of exposure to silica itself or the influence of parity on development of the disease. Misclassification of rheumatoid arthritis would further reduce the power of the study to detect a true risk. The diagnosis of rheumatoid arthritis was made by a physician with training and experience in the medical assessment of silica workers but did 
not follow standard epidemiological criteriasuch as those of the American Rheumatism Association. ${ }^{17}$ It is likely that a proportion of those categorised as cases of rheumatoid arthritis in the present study will have had other arthritides. ${ }^{18}$ In so far as these other conditions were unrelated to silica, the power would be reduced.

A major difficulty with the study is that workers were recorded as having rheumatoid arthritis only if they remained in pottery employment until the next medical examination. For men starting, and remaining, in a trade covered by the regulations, this period might be as little as 2 years. For others, particularly a woman who started work before 1950 and returned after time away to raise a family, this period might be more than 40 years. Assuming a greater propensity of those with rheumatoid arthritis to stop work or to change jobs, ${ }^{19}$ considerable numbers of cases in the cohort might fail to be identified through the system of periodic medicals. It was not practical to institute follow up of those who had left pottery employment. The ratio of male to female cases was higher than might be expected from population studies ${ }^{18}$ even after adjustment for the smaller female cohort but the overall proportion who developed the disease according to clinical diagnosis was not markedly lower than that in community studies. In a probability sample in the United States, ${ }^{20}$ which included subjects up to the age of 75, a prevalence of $0.8 \%$ was reported. In the United Kingdom, the prevalence from general medical practitioners' records was $0.7 \%$ for the age group 45-64 years. ${ }^{21}$ In the present study, $58 / 8325(0.7 \%)$ had this diagnosis. Although missed cases would affect the size and hence the power of the case-referent study, they would not necessarily introduce bias.

The absence of pre-employment or early employment information on rheumatoid arthritis for 25 of the 58 cases precludes any estimate of the date of onset of symptoms. It is possible that some or all of these had developed the condition before exposure to silica. A repeat of the analysis restricted to incident cases (the 33 cases for whom the absence of rheumatoid arthritis had been recorded at an earlier medical examination) produced results (not shown) that were at least as negative as those in the study as a whole. The absence of any evident effect of silica in those with the longest time from employment to diagnosis also suggests that the cases reported may have occurred sporadically in a group of workers who happened to be exposed to silica.

The significant, and consistent, excess in time away from work in the pottery industry in male cases is unexplained but may reflect a deliberate choice to seek less physically demanding work because of early musculoskeletal disease or during periods of exacerbation of symptoms. Information on pattern of employment before a diagnosis of rheumatoid arthritis does not seem to be available for other cohorts. In the present study, the finding of high risk in men with a history of work in the coal mining industry also seems most readily explained by a choice of pottery work as less demanding than mining. None of these ex-miners had radiographic changes suggestive of high exposure to coal or silica and examination of their time to diagnosis did not indicate an accelerated onset; both for ex-miners and other men in the cohort the mean time was 20.4 years.

Finally, it must be asked whether exposure to concentrations of silica in the pottery industry were sufficient to affect the health of the worker. In earlier studies exposure was sufficient to cause silicosis in those with rheumatoid arthritis. ${ }^{49}$ In the present pottery cohort, a relation between exposure and radiological change was found and an excess of lung cancer in those with higher concentrations of exposure. ${ }^{14}$ In the case-referent study reported here, no case had radiological changes suggestive of silicosis. The results presented are consistent with the proposition that where exposure is controlled sufficiently to prevent silicosis, excess cases of rheumatoid arthritis are unlikely to occur.

This study was funded, in part, by the United Kingdom Department of Social Security. Dr G L Burgess carried out the exposure estimation.

1 Collis EL. Industrial pneumoconioses with special reference to dust phthisis. London, UK: His Majesty's Medical Inspectorate, 1919.

2 Steenland K, Goldsmith DF. Silica exposure and autoimmune diseases. Am f Ind Med 1995;28:603-8.

3 Caplan A. Certain unusual radiological appearances in the chest of coal-miners suffering from rheumatoid arthritis. Thorax 1953;8:29-37.

4 Miall WE. Rheumatoid arthritis in males: an epidemiological study of a Welsh mining community. Ann Rheum Dis 1955;14:150-8

5 Sluis-Cremer GK, Hessel PA, Hnizdo E, et al. Relationship between silicosis and rheumatoid arthritis. Thorax 1986;41: 596-601.

6 Klockars M, Koskela RS, Jarvinen E, et al. Silica exposure and rheumatoid arthritis: a follow up study of granite workers 1940-81. BMF 1987;294:997-1000.

7 Steenland K, Nowlin S, Ryan B, et al. Use of multiple-cause mortality data in epidemiological analyses: US rate and proportion files developed by the National Institute for proportion files developed by the National Institute for Occupational Safety and Health and the Nato
Institute. Am f Epidemiol 1992;136:855-62.

8 Schroeder W, Franklin EC, McEwen C. Rheumatoid factors in patients with silicosis with round nodular fibrosis of the lung in the absence of rheumatoid arthritis. Arthritis Rheum lung in the absenc $1962 ; 5: 10-18$.

9 Jones RN, Turner-Warwick M, Ziskind M, et al. High prevalence of antinuclear antibodies in sandblasters' silicosis. Am Rev Respir Dis 1976;113:393-5.

10 Rosenman KD, Moore-Fuller M, Reilly MJ. Connective tissue disease and silicosis. Am f Ind Med 1999;35:375-381.

11 Meiklejohn A. Silicosis in the potteries. Br F Ind Med 1949; 6:230-40.

12 Silman AJ, Newman J, MacGregor AJ. Cigarette smoking increases the risk of rheumatoid arthritis. Arthritis Rheum 1996;39:732-5.

13 Spector TD, Roman E, Silman AJ. The pill, parity, and rheumatoid arthritis. Arthritis Rheum 1990;33:782-9.

14 Cherry NM, Burgess GL, Turner S, et al. Crystalline silica and risk of lung cancer in the potteries. Occup Environ Med 1998;55:779-85.

15 Burgess GL. Development of an exposure matrix for respirable crystalline silica in the British pottery industry. Ann able crystalline silica in the
Occup Hyg 1998;42:209-17.

16 International Labour Office. Guidelines for the use of ILO international classification of radiographs of pneumoconioses. Geneva: ILO, 1980. (Occupational Safety and Health Series No 22.)

17 Arnett FC, Edworthy SM, Bloch DA, et al. The American Rheumatism Association 1987 revised criteria for the classification of rheumatoid arthritis. Arthritis Rheum 1988; 31:315-24.

18 Lawrence RC, Hochberg MC, Kelsey JL, et al. Estimates of the prevalence of selected arthritic and musculoskeletal diseases in the United States. Fournal of Rheumatology 1989;16:427-41.

19 Yelin EH. Musculoskeletal conditions and employment. Arthritis Care Res 1995;8:311-17.

20 Cunnigham LS, Kelsey JL. Epidemiology of musculoskeletal impairments and associated disability. Am $\mathcal{F}$ Public Health 1984;74:574-9.

21 McCormack A, Fleming D, Charlton J. Morbidity statistics from general practice 1991-2. London: The Stationery Office, 1995. 